\title{
UDO DO VANT PARA IDENTIFICAÇÃO DAS MANIFESTAÇÕES PATOLÓGICAS DE FACHADAS: ESTUDO DE CASO EM EDIFICAÇÕES MULTIFAMILIARES
}

\author{
B. G. WALTER ${ }^{1 *}$, G. SCHAEFFER ${ }^{2}$, R. CHRIST $^{3}$, F. PACHECO $^{3}$, B. F. TUTIKIAN ${ }^{3}$ \\ ${ }^{1}$ Graduação Arquitetura e Urbanismo, UNISINOS, São Leopoldo, Brasil \\ ${ }^{2}$ Eng. Civil, UNISINOS, São Leopoldo, Brasil \\ ${ }^{3}$ Pós graduação - Doutorado em Engenharia Civil, itt Performance UNISINOS, São Leopoldo, Brasil
}

\section{RESUMO}

Nas últimas décadas, a incorporação de máquinas no processo produtivo resultou em redução de desperdícios, aperfeiçoamento de processos e aumento da produtividade em diversos setores da sociedade. Percebe-se na inspeção predial, em específico a inspeção em fachadas, uma área que pode avançar em termos de técnologia, visto que em muitos casos, ainda depende de andaimes, cordas e rapel para ser realizada. Tais tarefas colocam em risco os profissionais, além de causar danos à logística, gerando custos e elevado tempo. Como alternativa para que a identificação de manifestações patológicas em fachadas seja rápida, segura e eficiente esta pesquisa aponta o uso de VANT (veículo aéreo não tripulado) como um instrumento auxiliar para o levantamento das manifestações patológicas em edificações. Realizou-se captação de vídeos e imagens das fachadas, sendo estas analisadas visando diagnosticar os danos, prever prognósticos de problemas, bem como possíveis profilaxias e terapias. Foram analisadas fachadas de três edificações cujos sistemas construtivos são de concreto armado e alvenaria de vedação com revestimento argamassado de diferentes idades e alturas. Como resultado, foi constatado que a captação de imagens do VANT possui amplo potencial de utilização possibilitando a identificação, pelo profissional, de manifestações como manchas de sujeira, expansão no revestimento e/ou pintura, falhas de execução e fissuras tanto horizontais como verticais, ampliando a eficácia das tarefas de inspeção.

Palavras clave: inspeção predial, VANT, manifestações patológicas, patologia das edificações.

\begin{abstract}
In the last decades, the incorporation of machines in the productive process has resulted in reduction of waste, improvement of processes and increase of productivity in several sectors of society. It can be noticed in the inspection of buildings, in particularly the inspection of façades, an area that can advance in terms of technology, since in many cases, it still depends on scaffolding, ropes and abseiling to be carried out. These tasks put at risk the professionals, besides causing damage to the logistics, generating costs and high time. An alternative to transform the identification of pathological manifestations in façades faster, safer and more efficient, this research points out the use of UAV (Unmanned Aerial Vehicle) as an adjuvant instrument for the survey of pathological manifestations in buildings. Videos and images of the façades were captured and analyzed to diagnose the damages, predict prognosis of problems, as well as possible prophylaxis and therapies. Façades of three buildings, whose constructive systems are of reinforced concrete and sealing masonry with mortar coating of different ages and heights, were analyzed. As a result, it was verified that the image collection of the UAV has a wide potential of use allowing the identification by the professional of manifestations such as dirt spots, coating expansion and/or painting, execution faults and horizontal and vertical cracks, effectiveness of inspection tasks.
\end{abstract}

Keywords: building inspection, UAV, pathological manifestations, pathology of buildings. 


\section{INTRODUÇÃO}

Para a realização de inspeções de fachadas, normalmente são utilizados métodos em campo por inspeção direta sobre as edificações, o que muitas vezes implica em grandes custos e em riscos de acidentes. As edificações de grande porte e elevadas alturas, tornam alguns locais difíceis de serem acessados, o que gera complexidade na inspeção para visualizar possíveis manifestações patológicas. (COSTA, 2014)

Existem diversas estratégias desenvolvidas para desempenhar a manutenção de fachadas, entre elas: utilização de andaimes fachadeiros, utilização de lunetas, binóculos e máquinas fotográficas. Mais recentemente estão sendo utilizadas plataformas articuladas, onde o inspetor comanda o aparelho a partir da gôndola, que se situa na extremidade da lança. Segundo Teles (2010), para inspecionar fachadas há vários métodos, como métodos simples, como escadas e cavaletes que são de baixo custo e facilidade no uso, porém, existe a desvantagem de ter um alcance limitado e a segurança precisa ser redobrada.

As fachadas de edifícios de multipavimentos precisam ser inspecionadas de maneira que seja permitido observar toda sua extensão vertical, para isso, é preciso de algum transporte vertical, entretanto, é necessário um planejamento de como irá ser realizado o acesso, pois ocasiona em custos e prazos. (TELES, 2010). Neste sentido, o uso da técnica de VANT (Veículos aéreos não tripuláveis) apresenta vantagens significativas, como a geração de documentação fotográfica e de pré-projetos, mapeamento com precisão e apuração de inspeções.

Veículo aéreo não tripulado é um termo geral que identifica as aeronaves que não necessitam de tripulação, frequentemente utilizadas em casos que apresentam maiores riscos ou que são de difícil acesso. (FURTADO et al., 2008). Segundo Galvão (2016), os VANTs propiciam uma inspeção mais barata e segura. Uma das grandes vantagens é a segurança apresentada por esse instrumento, pois não é necessário contratar profissionais para fazer inspeção com uso de rapel, andaimes, cordas, etc.

Como alternativa para que a identificação de manifestações patológicas em fachadas seja rápida, segura e eficiente esta pesquisa aponta o uso de VANT (veículo aéreo não tripulado) como um instrumento auxiliar para o levantamento das manifestações patológicas em edificações. Este estudo foi realizado através da análise dos resultados de inspeções feitas em fachadas de edificações somente de alvenaria de vedação com revestimento argamassado.

\section{MANIFESTAÇÕES PATOLÓGICAS EM FACHADAS}

Segundo Parissenti (2016), os problemas que podem ocorrer nas edificações aparecem desde a concepção até o decorrer de sua vida útil. Por isso, todos os elementos e sistemas de uma edificação necessitam de manutenção, para garantir a segurança e estabilidade do desempenho que é fornecido para garantir sua vida útil.

A proliferação de bolores nas superfícies é uma manifestação de ocorrência significativa nas fachadas. Segundo Shirakawa (1999), o desenvolvimento de fungos e de bolores em revestimentos internos ou de fachadas causa alteração estética de tetos e paredes, formando manchas escuras indesejáveis e muitas vezes acarreta a desvalorização comercial do imóvel. Outro fator importante a ser considerado na presença de fungos nas edificações, é a possibilidade de transmissão de doenças causadas por estes microrganismos.

Nos revestimentos externos, estas manifestações são mais comuns em função da exposição deste sistema às intempéries e condições do meio ambiente. Pacheco e Vieira (2015) expõem que as fachadas são os elementos que estão mais sujeitos aos agentes externos como a chuva, a variação de temperatura, o sol e a umidade, pois elas funcionam como um envelope das edificações. 
Sendo assim, a fachada é um componente da edificação que exige muita atenção, sua degradação pode gerar várias consequências, que podem ir desde pequenas fissuras até a queda de placas devido ao descolamento de revestimento, podendo causar graves acidentes, colocando em risco a vida de pessoas.

\section{MÉTODO}

Para o estudo de caso, foram avaliadas três edificações constituídas em estrutura de concreto armado, com o fechamento em alvenaria de vedação e as fachadas de revestimento argamassado com acabamento de pintura, materiais comumente utilizados em nosso país. Estes tipos de materiais apresentam execuções criteriosas, onde muitas vezes não são obedecidas, trazendo para as edificações as consequências de manifestações patológicas. O veículo aéreo não tripulado utilizado no estudo foi o modelo Phantom 3 Standard, conforme Figura 1. A partir da câmera acoplada no equipamento foram realizados registros fotográficos para a posterior análise dos problemas encontrados.

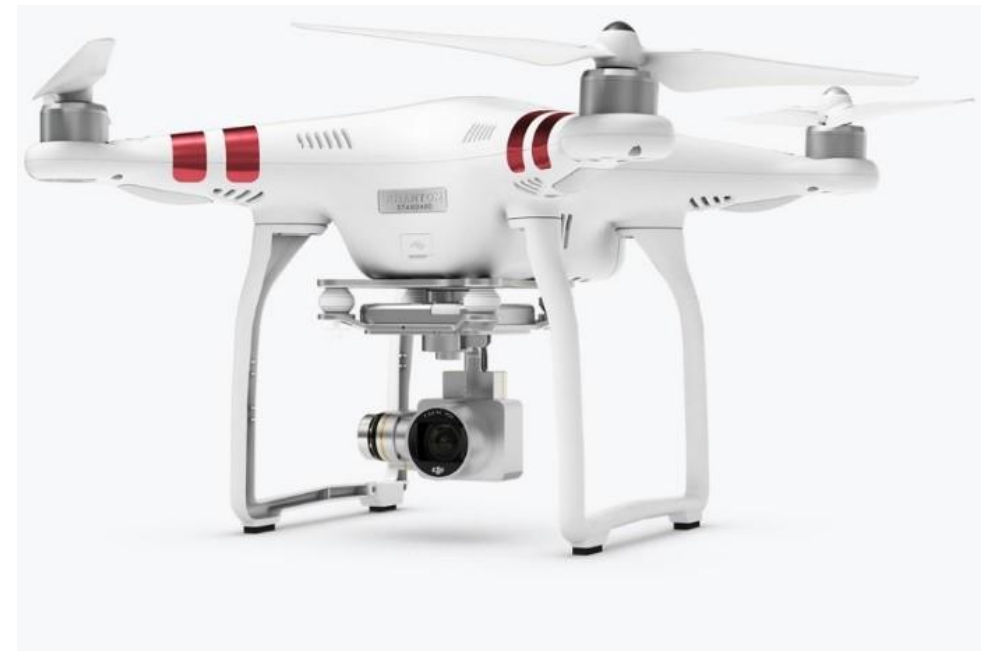

Figura 1 - Phantom 3 Standard

Fonte: Imagem adaptada do site DJI, 2017.

O modelo Phantom 3 Standart pesa 1,2kg, contando com uma câmera acoplada que captura imagens de 12 megapixels, podendo gravar vídeos HD 2.7k. Contém 4 rotores que impulsionam o drone a uma velocidade de até $16 \mathrm{~m} / \mathrm{s}$, podendo chegar a uma altura de até $1 \mathrm{~km}$. Foram utilizadas proteções nas 4 hélices para realizar uma melhor avaliação na inspeção, obtendo maior segurança ao chegar perto das fachadas em estudo.

A duração máxima de voo do equipamento é de aproximadamente 25 minutos em função da bateria, a qual remete uma informação quando é preciso retornar a base. As imagens do veículo aéreo não tripulado são visualizadas em tempo real, enviadas a partir do sistema de GPS para o celular ou tablete que é conectado junto ao controle remoto.

A fim de obter um estudo conveniente, para a obtenção do diagnóstico das manifestações patológicas, foram realizadas anamnese e/ou pesquisas bibliográficas com o intuito de levantar informações das prováveis causas dos problemas encontrados.

Com o diagnóstico elaborado, foram realizados os prognósticos das manifestações patológicas, para que seja esclarecida a possível evolução do problema, caso este não seja solucionado.

Por fim, foram sugeridas as possíveis terapias dos problemas, com o intuito identificar a necessidade de uma restauração, reforço ou reparação da manifestação avaliada. A profilaxia foi abordada para que futuras edificações desse mesmo porte e materiais possam ter ciência de como prevenir estes problemas. A metodologia utilizada foi adequada ao método de Lichtenstein (1986) que segue um fluxograma para 
resolução dos problemas patológicos, conforme Figura 2.

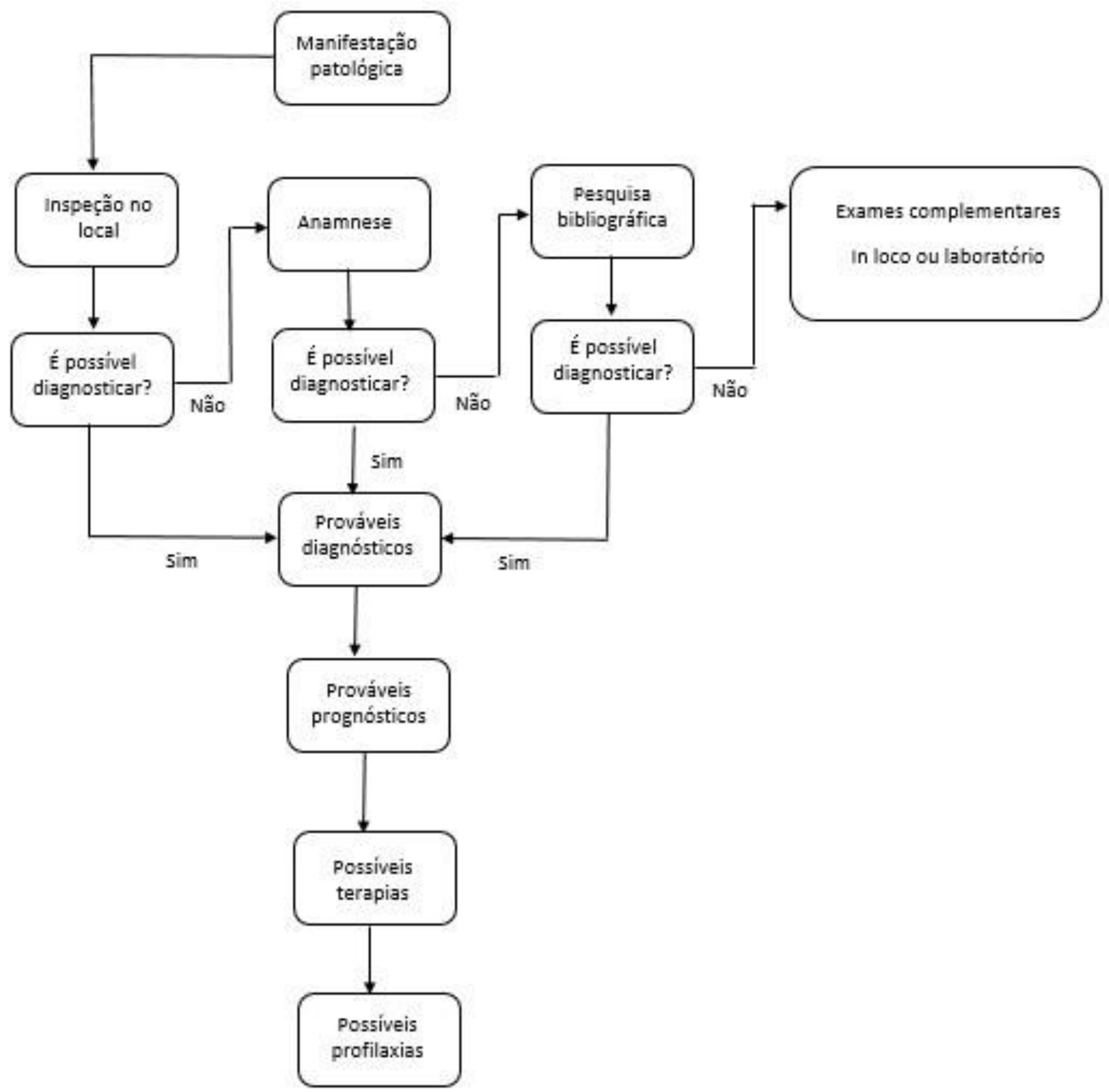

Figura 2 -Fluxograma de atuação para a resolução dos problemas patológicos

\subsection{Edificação "A"}

A edificação em estudo (Figura 4) está localizada no centro da cidade de Feliz, Rio Grande do Sul. Contém uma atual edificação multifamiliar vizinha e poucas vegetações em seu entorno. Foi finalizada no ano de 1993, no entanto, possui 24 anos, com uma manutenção na fachada realizada no ano de 2008, onde foi substituído o revestimento anterior, que era composto de revestimento fulget, pelo revestimento atual, composto de argamassa com textura acrílica.

É constituída pelo térreo e mais 4 pavimentos, executada com sistema estrutural em concreto armado e alvenaria de vedação com tijolos maciços.

As fachadas estão localizadas nas direções oeste (entrada principal), leste (fundos), e as fachadas laterais nas direções norte e sul. Não foi possível fotografar a fachada localizada na direção leste, pelo fato de conter uma edificação vizinha impedindo a visão completa deste local.

Foram realizadas duas inspeções no mês de julho. A primeira inspeção foi realizada em 20 minutos e a 
segunda foi somente para reaver locais nos quais as imagens coletadas da primeira não ficaram evidentes. Realizou-se apenas uma subida do veículo aéreo não tripulado, gravando um vídeo de todas as fachadas para posterior análise e captura de foto das manifestações encontradas. Além da análise feita das imagens capturadas pelo VANT, foi disponibilizado o memorial descritivo da edificação, levando a uma melhor avaliação das manifestações encontradas.

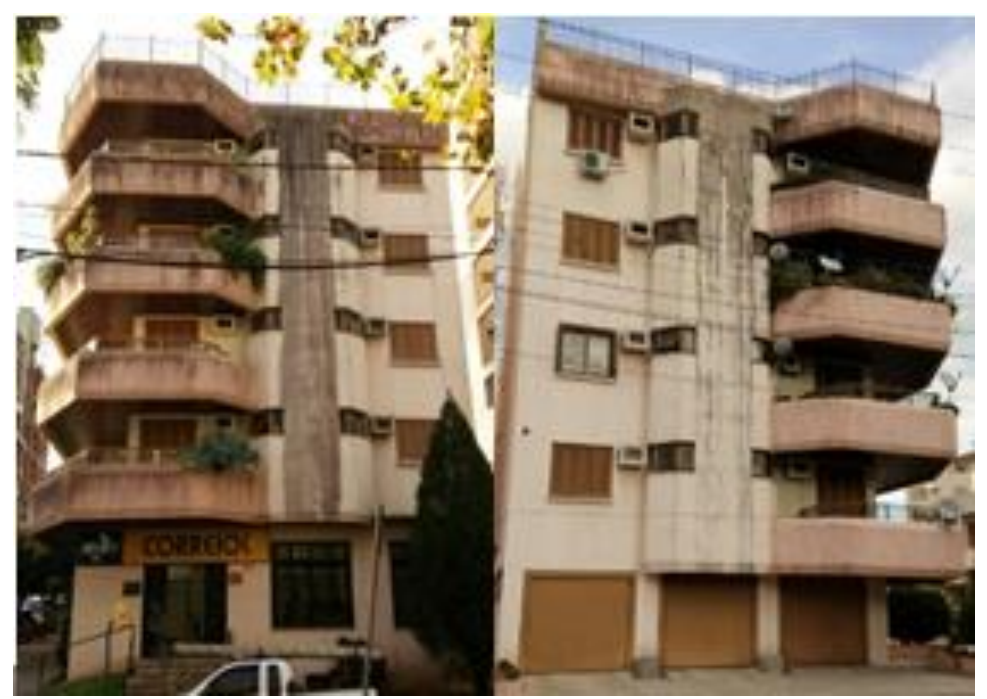

Figura 3. Fachada sul e norte, respectivamente

\subsection{Edificação "B"}

Para análise da edificação "B", buscou-se levantar por meio de entrevistas com o engenheiro e demais responsáveis pela edificação, informações sobre as características mais relevantes, a fim de obter as possíveis causas das manifestações levantadas pelo veículo aéreo não tripulado. Também foi disponibilizado o memorial descritivo, levando a uma melhor avaliação das manifestações encontradas. Foram realizadas duas inspeções no mês de julho. A primeira inspeção foi realizada em 30 minutos e a segunda foi somente para reaver locais nos quais as imagens coletadas da primeira não ficaram evidentes. Realizou-se duas subidas do veículo aéreo não tripulado, gravando um vídeo de todas as fachadas para posterior análise e captura de fotos das manifestações encontradas.

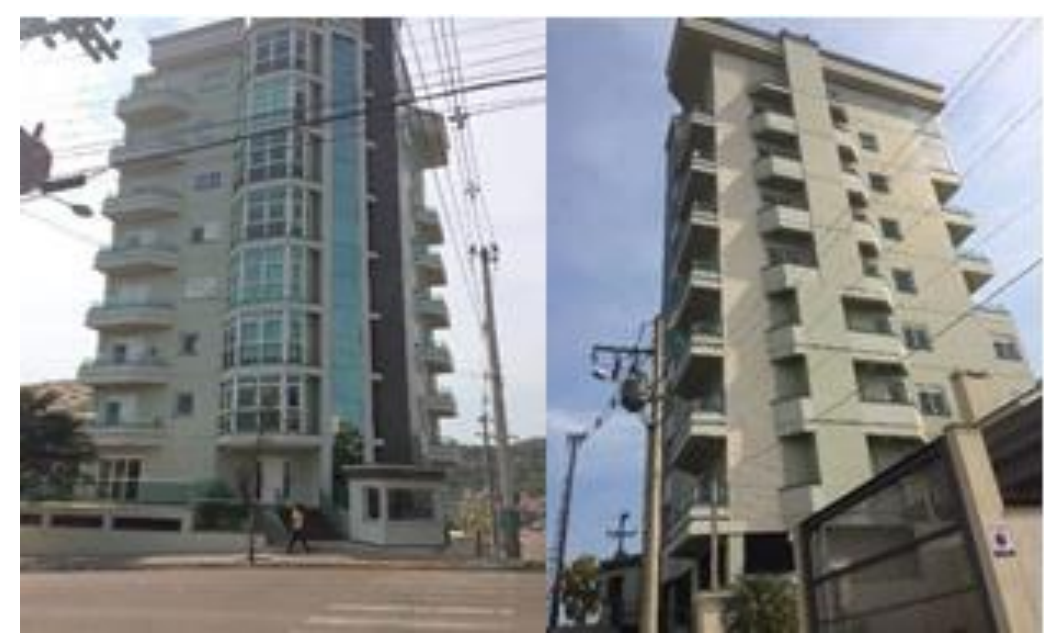

Figura 4. Fachadas oeste e leste, respectivamente 


\subsection{Edificação "C"}

Foi realizada somente uma inspeção no mês de julho, concluída em 25 minutos. Realizou-se apenas uma subida do veículo aéreo não tripulado, gravando um vídeo de duas fachadas para posterior análise e captura de foto das manifestações encontradas.

Para análise da edificação "C", buscou-se levantar por meio de entrevistas com o proprietário, informações sobre as características mais relevantes, a fim de obter as possíveis causas das manifestações captadas pelo veículo aéreo não tripulado e identificadas pelo profissional responsável. $\mathrm{O}$ mesmo apresentou projetos e memoriais, levando a uma melhor avaliação das manifestações encontradas.

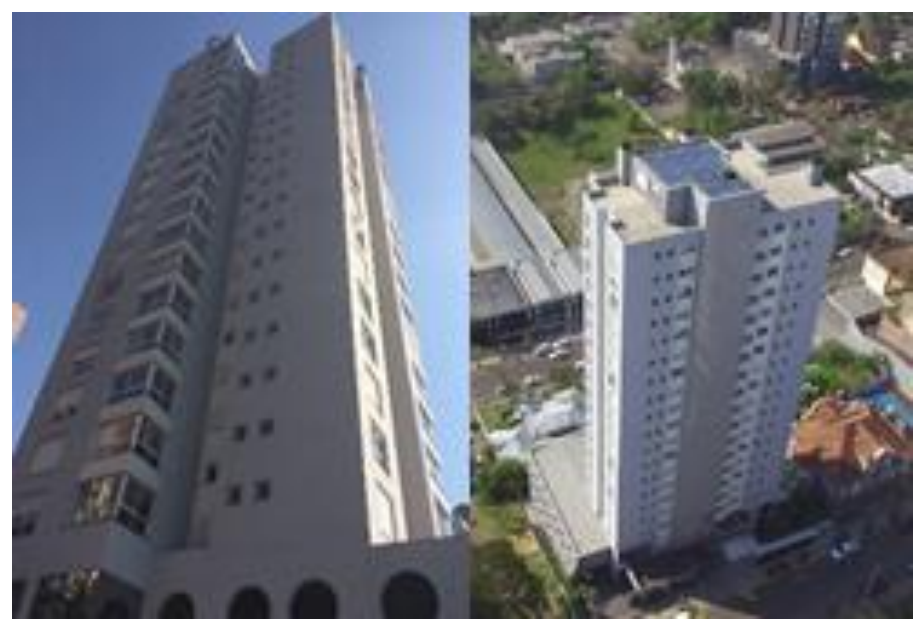

Figura 5. Fachadas sul e norte, respectivamente

\section{ANÁLISE DE RESULTADOS}

A seguir serão apresentados os resultados obtidos nesta pesquisa, prováveis diagnósticos e prognósticos e as possíveis profilaxias e terapias dos problemas. Todas as manifestações patológicas registradas foram identificadas com o auxílio do Veículo Aéreo Não Tripulado (VANT). Estas edificações foram escolhidas por sua composição construtiva semelhante.

As manifestações identificadas nas edificações "A", "B" e "C" em estudo são apresentadas em imagens coletadas pelo veículo aéreo não tripulado utilizado nas inspeções in loco. As inspeções foram realizadas no mês de julho do ano de 2017, pela autora do trabalho e por um engenheiro civil apto.

\subsection{Edificação "A"}

Foram identificadas manchas de sujeira e fissuras horizontais no revestimento nas fachadas sul, norte e leste do edifício "A" e expansão no revestimento na fachada oeste. As figuras 6,7, 8 e 9 apresentam as manifestações citadas acima.

É possível que estas fissuras horizontais sejam consequência de uma movimentação higroscópica ou da hidratação retardada do óxido de magnésio de cal que ocasiona expansão na argamassa de assentamento. Podem ocorrer mais ao topo das paredes devido aos esforços de compressão originários do peso próprio da alvenaria. prováveis causas pode ser a movimentação higroscópica. 


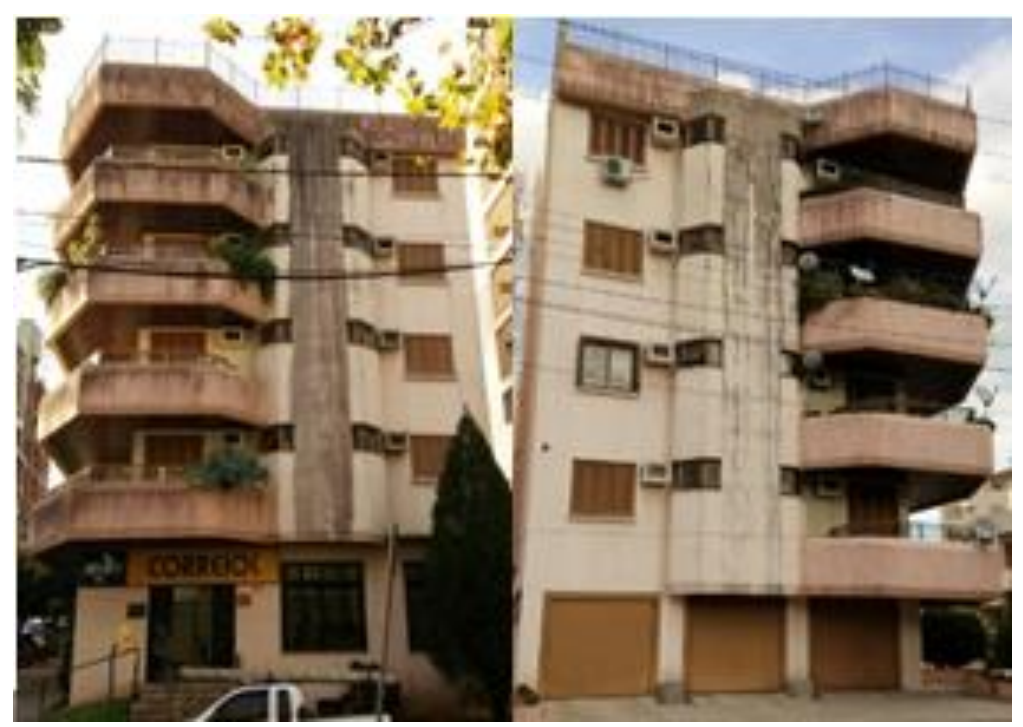

Figura 6. Manchas de sujeira identificadas na fachada Sul e Norte, respectivamente

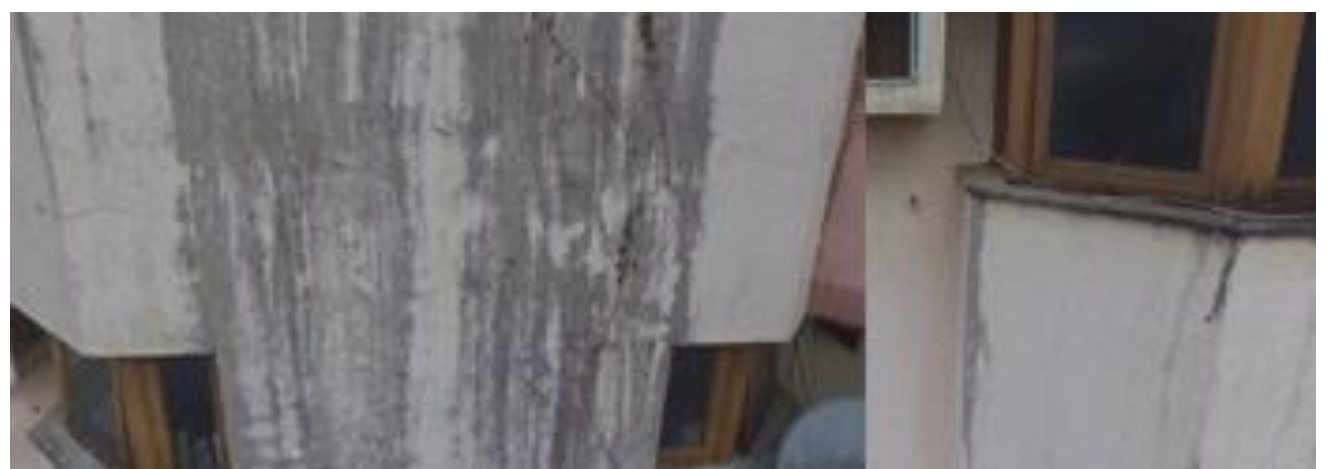

Figura 7. Fissuras horizontais e manchas identificadas na fachada oeste, respectivamente

Já as manchas de sujeira são decorrentes principalmente da poluição atmosférica, porém outros fatores podem contribuir com o seu surgimento como o vento, a chuva, a porosidade do revestimento e o próprio formato das fachadas com suas reentrâncias ou superfícies horizontais. De acordo com Britez et al (2017), deve ser considerado na fase de projeto, como os detalhes arquitetônicos podem contribuir para o escoamento de água, reduzindo o contato com os elementos construtivos e consequentemente a chance de manchamento, fissuração, entre outros.

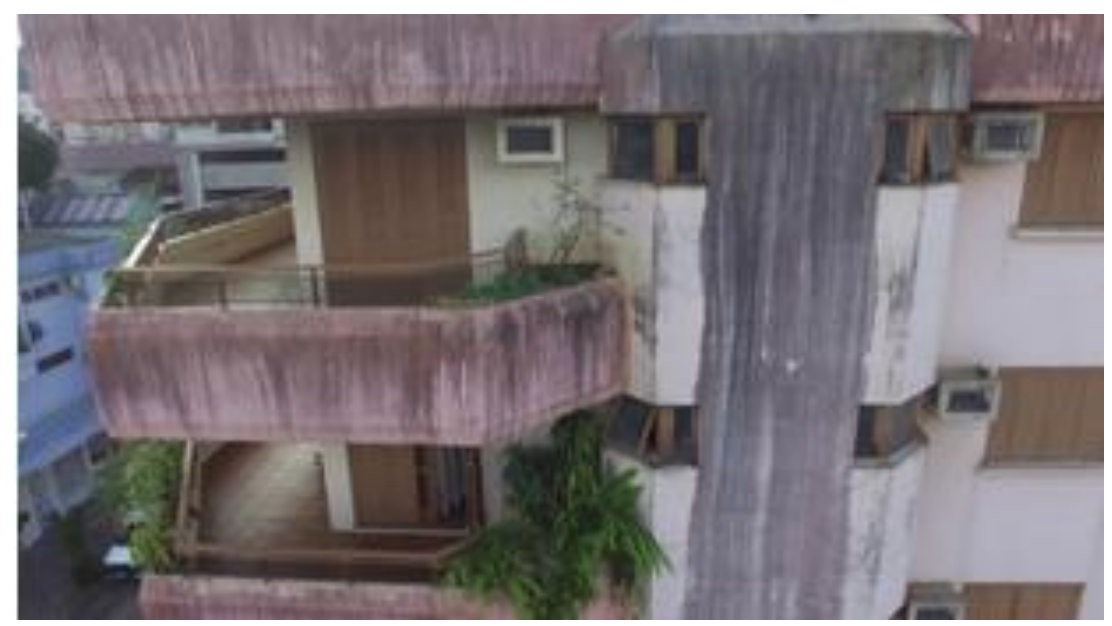

Figura 8. Manchas de sujeira identificadas na fachada oeste 
A expansão do revestimento, identificada na fachada oeste, pode ter sido causa de uma má limpeza do substrato para execução na troca do antigo revestimento de fulget por um revestimento argamassado. Outro fator seria o esquecimento de materiais que podem ocasionar a expansão da argamassa, como madeiras, pregos, etc. Ainda assim, mesmo com os dados recolhidos do memorial descritivo da edificação e das imagens feitas pelo VANT, neste caso, para a obtenção de um diagnóstico mais preciso, é de extrema necessidade a realização de uma inspeção invasiva, onde será retirado o material com a finalidade se verificar a razão para este desprendimento.

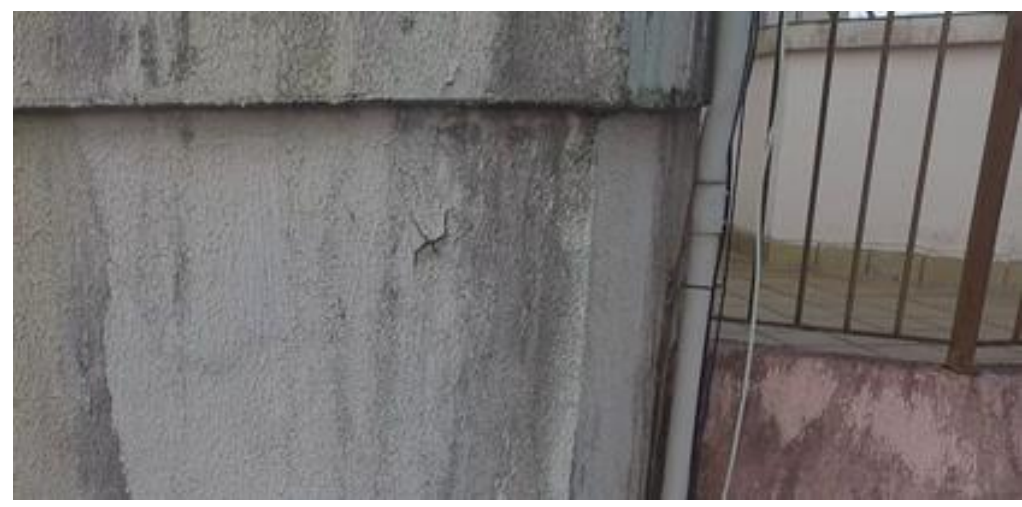

Figura 9. Expansão do revestimento e/ou pintura identificado na fachada oeste

Segue na seguinte tabela (Tabela 1) os prováveis diagnósticos, prováveis prognósticos e possíveis terapias, aferidas às manifestações patológicas identificadas com o auxílio do equipamento VANT.

Tabela 1. Manifestações Identificadas

\begin{tabular}{|c|c|c|c|}
\hline $\begin{array}{l}\text { Manifestações } \\
\text { Patológicas } \\
\text { Identificadas }\end{array}$ & Prováveis Diagnósticos & Prováveis Prognósticos & Possíveis Terapias \\
\hline \multirow{4}{*}{ Manchas de Sujeira } & \multirow{4}{*}{$\begin{array}{c}\text { Inexistência de projeto de } \\
\text { fachada e a falta de } \\
\text { manutenção }\end{array}$} & Proliferação de fungos & \multirow{4}{*}{$\begin{array}{l}\text { Reparar a pintura das } \\
\text { fachadas }\end{array}$} \\
\hline & & Umidade & \\
\hline & & Infiltração & \\
\hline & & Desvalorização comercial & \\
\hline \multirow[b]{4}{*}{ Fissuras Horzontais } & \multirow[b]{4}{*}{$\begin{array}{c}\text { Expansão da argamassa } \\
\text { de assentamento ou } \\
\text { movimentação } \\
\text { higroscópica. }\end{array}$} & Penetração de água & \multirow{4}{*}{$\begin{array}{l}\text { Fissuras estabilizadas: } \\
\text { preencher com uma nova } \\
\text { camada de revestimento; } \\
\text { Fissuras não } \\
\text { estabilizadas: é necessário } \\
\text { realizar o preenchimento } \\
\text { desta com mastiques e } \\
\text { colocar revestimento } \\
\text { elástico e armado }\end{array}$} \\
\hline & & Queda de placas & \\
\hline & & Infiltrações & \\
\hline & & Proliferação de bolores. & \\
\hline $\begin{array}{l}\text { Expansão do } \\
\text { revestimento } \\
\text { argamassado }\end{array}$ & Má limpeza do substrato & $\begin{array}{l}\text { Descolamentos do } \\
\text { revestimento }\end{array}$ & $\begin{array}{l}\text { Apenas após a verificação } \\
\text { da real razão, é possível } \\
\text { seguir com uma solução. }\end{array}$ \\
\hline
\end{tabular}

\subsection{Edificação "B"}

Foram identificadas fissuras inclinadas nas extremidades das esquadrias em todas as fachadas e fissuras horizontais na interface viga/alvenaria na fachada leste.

A decorrência das fissuras inclinadas nas extremidades das esquadrias, de acordo com as anamneses realizadas, está diretamente ligada com a ausência de vergas e contravergas. Os vãos das janelas são lugares onde geram concentrações de tensões, então, a inexistência de vergas e contravergas fazem com 
que as tensões não sejam corretamente distribuídas e as mesmas acabam gerando estas manifestações. As fissuras identificadas estão descriminadas nas figuras 10 e 11.

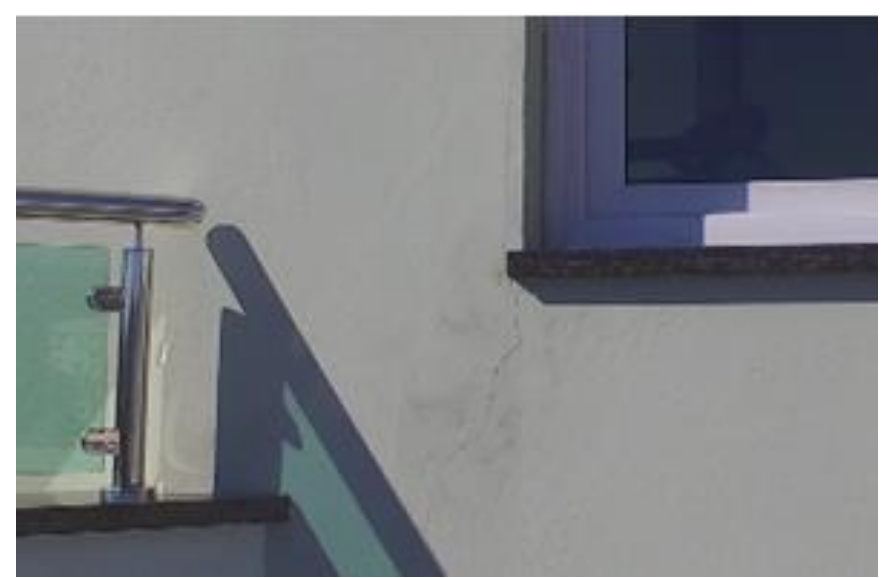

Figura 10. Fissuras inclinadas identificadas nas extremidades das esquadrias

Como a fissura acontece na interface alvenaria/viga, a possível causa do surgimento desta fissura é pela movimentação térmica dos materiais de construção com diferentes propriedades térmicas. A laje e as vigas estão engastadas e as armaduras combateram esta variação (Figura 11). Porém a viga está apoiada a alvenaria e não possuindo restrições.

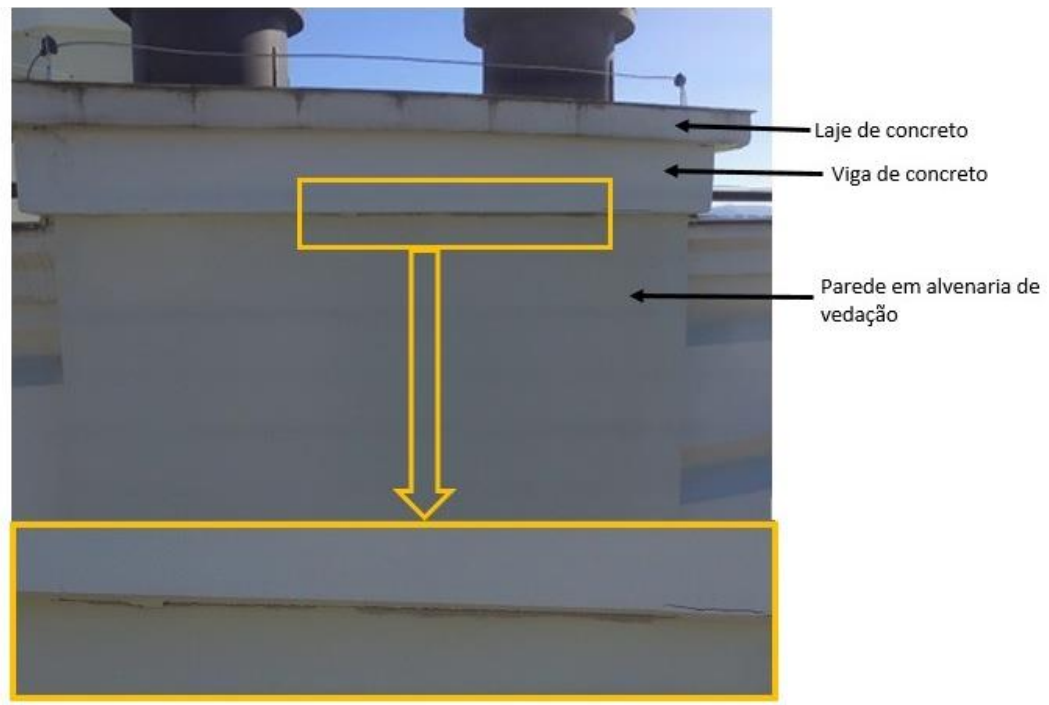

Figura 11. Manifestação patológica fissura horizontal na interface viga/alvenaria

Os resultados verificados nessa habitação concordam com a afirmação de Carvalho et al (2017), que citam que as principais manifestações patológicas que ocorrem nas fachadas são as manchas (causadas por microorganismos ou infiltrações), assim como, a presença de fissuras, descolamento e queda do revestimento.

Da Paz et al (2016) perceberam, ao analisar edificações com danos oriundos pela ação da água, a formação de fissuras entre elementos estruturais e principalmente na base da alvenaria, causados pelo acúmulo de água e possível movimentação dos elementos construtivos, além da sujidade e manchamento verificados na fachada, indicando a possibilidade de existência de microorganismos. Segue na Tabela 2 os prováveis diagnósticos, prováveis prognósticos e possíveis terapias, aferidas às manifestações patológicas identificadas com o auxílio do equipamento VANT. 
Tabela 2. Manifestações identificadas

\begin{tabular}{|c|c|c|c|}
\hline $\begin{array}{l}\text { Manifestações } \\
\text { Patológicas } \\
\text { Identificadas } \\
\end{array}$ & Prováveis Diagnósticos & Prováveis Prognósticos & Possíveis Terapias \\
\hline \multirow{4}{*}{$\begin{array}{l}\text { Fissuras Inclinadas nas } \\
\text { Extremidades das } \\
\text { Esquadrias }\end{array}$} & \multirow{4}{*}{$\begin{array}{c}\text { Ausência de vergas e } \\
\text { contravergas }\end{array}$} & $\begin{array}{l}\text { Umidade no interior do } \\
\text { revestimento }\end{array}$ & \multirow{4}{*}{$\begin{array}{c}\text { Execução de vergas e } \\
\text { contravergas }\end{array}$} \\
\hline & & $\begin{array}{l}\text { Descolamentos do } \\
\text { revestimento }\end{array}$ & \\
\hline & & $\begin{array}{l}\text { Infiltração no interior da } \\
\text { edificação }\end{array}$ & \\
\hline & & Proliferação de mofos & \\
\hline \multirow{2}{*}{$\begin{array}{c}\text { Fissuras Horizontais na } \\
\text { Interface } \\
\text { Viga/Alvenaria }\end{array}$} & \multirow{2}{*}{$\begin{array}{l}\text { Movimentação térmica } \\
\text { dos materiais de } \\
\text { construção com } \\
\text { diferentes propriedades } \\
\text { térmicas }\end{array}$} & $\begin{array}{l}\text { Descolamento do } \\
\text { revestimento }\end{array}$ & \multirow{2}{*}{$\begin{array}{c}\text { Preenchimento com } \\
\text { mastiques e colocar } \\
\text { revestimento elástico e } \\
\text { armado }\end{array}$} \\
\hline & & Infiltrações & \\
\hline
\end{tabular}

\subsection{Edificação "C"}

Os locais onde foram encontradas as manifestações patológicas como fissuras horizontais, inclinadas, verticais e falhas no revestimento argamassado foram nas fachadas sul e norte da edificação "C". Com as anamneses realizadas, foi possível verificar que o local onde foram observadas estas falhas, existe um pilar e uma viga. Então, pode ocorrer de acumular água e umidade nestes locais, e se caso a armadura dos elementos estruturais do local não estiverem devidamente cobertas, pode ocasionar uma futura corrosão destas, consequentemente gerando problemas estruturais futuros para a edificação. Como a edificação foi revestida com argamassa, a provável causa para este problema é a falha na execução do revestimento. $\mathrm{Na}$ imagem é possível identificar a presença de tinta na falha, o que evidencia que este revestimento não se desprendeu.

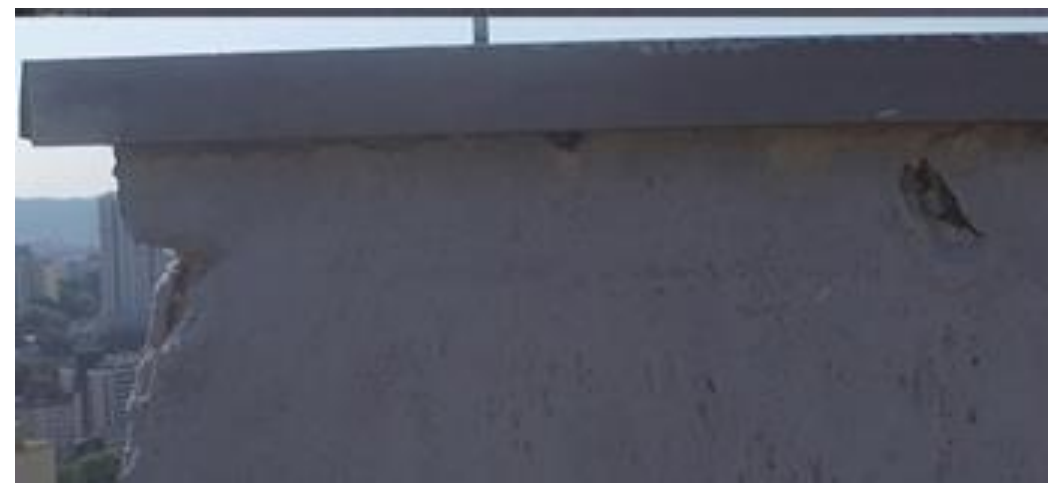

Figura 12. Falha no revestimento argamassado na fachada sul

O prognóstico para fissuras inclinadas na abertura de uma esquadria sucede da mesma forma que na manifestação identificada no edifício "B", os vãos das janelas geram concentrações de tensões, e a falta de vergas e contravergas faz com que as tensões não sejam corretamente distribuídas e as mesmas acabam gerando estas fissuras (Figura 13). 
Figura 13. Fissura horizontal nas aberturas das esquadrias na fachada sul

A provável causa desta fissura vertical na interface concreto/alvenaria é a movimentação térmica dos materiais com diferentes propriedades. Qualquer fissura existente pode promover infiltração de água para seu interior, permitindo que ocorra um aumento da mesma, podendo futuramente ocasionar até possíveis descolamentos e infiltração no interior da edificação (Figura 14).

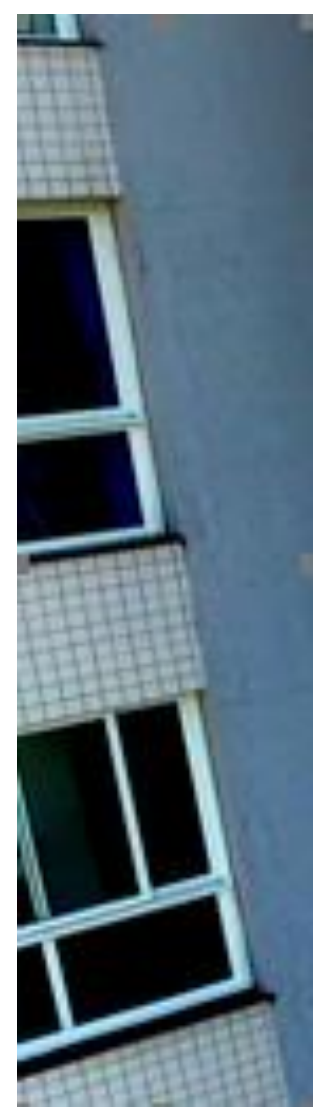

Figura 14 - fissura vertical na interface concreto/alvenaria na fachada norte

Segue na seguinte tabela (Tabela 03) os prováveis diagnósticos, prováveis prognósticos e possíveis terapias, aferidas às manifestações patológicas identificadas com o auxílio do equipamento VANT. 
Tabla 3.

\begin{tabular}{|c|c|c|c|}
\hline $\begin{array}{l}\text { Manifestações } \\
\text { Patológicas } \\
\text { Identificadas }\end{array}$ & Prováveis Diagnósticos & $\begin{array}{c}\text { Prováveis } \\
\text { Prognósticos }\end{array}$ & Possíveis Terapias \\
\hline \multirow{5}{*}{ Fissuras Horizontais } & \multirow{5}{*}{ Concentração de tensões } & Umidade & \multirow{5}{*}{$\begin{array}{l}\text { Execução de vergas e } \\
\text { contravergas }\end{array}$} \\
\hline & & $\begin{array}{l}\text { Descolamentos do } \\
\text { revestimento }\end{array}$ & \\
\hline & & Quedas de placas & \\
\hline & & Infiltração & \\
\hline & & Proliferação de mofos & \\
\hline \multirow{3}{*}{ Fissuras Inclinadas } & \multirow{3}{*}{ Concentração de tensões } & Umidade & \multirow{3}{*}{$\begin{array}{l}\text { Preencher com uma nova } \\
\text { camada de revestimento }\end{array}$} \\
\hline & & $\begin{array}{l}\text { Infiltração no interior } \\
\text { da edificação }\end{array}$ & \\
\hline & & Proliferação de mofos & \\
\hline \multirow{3}{*}{ Fissuras Verticais } & \multirow{3}{*}{$\begin{array}{l}\text { Movimentação térmica } \\
\text { dos materiais com } \\
\text { diferentes propriedades }\end{array}$} & $\begin{array}{c}\text { Descolamentos do } \\
\text { revestimento }\end{array}$ & \multirow{3}{*}{$\begin{array}{l}\text { Preencher com uma nova } \\
\text { camada de revestimento }\end{array}$} \\
\hline & & $\begin{array}{c}\text { Infiltração no interior } \\
\text { da edificação }\end{array}$ & \\
\hline & & Proliferação de mofos & \\
\hline \multirow{2}{*}{$\begin{array}{c}\text { Falhas no } \\
\text { Revestimento } \\
\text { Argamassado }\end{array}$} & \multirow{2}{*}{$\begin{array}{l}\text { Falha na execução do } \\
\text { revestimento }\end{array}$} & Umidade & Limpeza do local \\
\hline & & Corrosão & Fechamento da falha \\
\hline
\end{tabular}

\section{SÍNTESE DOS RESULTADOS}

As manifestações identificadas nas três edificações estudadas serão apresentadas em um Quadro Resumo (Tabela 4) para melhor visualização de todos os resultados coletados com o auxílio do veículo aéreo.

Tabela 4. Quadro Resumo das manifestações patológicas identificadas

\begin{tabular}{|c|c|}
\hline \multicolumn{2}{|c|}{ Quadro Resumo } \\
\hline Manifestações Patológicas & Prováveis Diagnósticos \\
\hline Manchas de sujeira nas fachadas & Inexistência de projeto de fachada \\
\hline \multirow{3}{*}{ Expansão no Revestimento e/ou pintura } & Má limpeza do substrato \\
\hline & Esquecimento de materiais \\
\hline & $\begin{array}{l}\text { Realizar exames complementares para } \\
\text { diagnóstico correto }\end{array}$ \\
\hline \multirow{3}{*}{ Fissuras Horizontais no Revestimento Argamassado } & Movimentação higroscópia \\
\hline & Expansão da argamassa de assentamento \\
\hline & $\begin{array}{l}\text { Realizar exames complementares para } \\
\text { diagnóstico correto }\end{array}$ \\
\hline Fissruas Inclinadas nas Extremidades das Esquadrias & Ausência de verga e contraverga \\
\hline Fissura Horizontal na Interface Viga/Alvenaria & Movimentação térmica \\
\hline Falha no Revestimento & Falha na execução \\
\hline $\begin{array}{c}\text { Fissuras Horizontais e Inclinadas nas Aberturas das } \\
\text { Esquadrias }\end{array}$ & Utilização deficiente de verga e contraverga \\
\hline Fissura Vertical na Interface Concreto/Alvenaria & Movimentação térmica \\
\hline
\end{tabular}


Na edificação “A”, a mais antiga, com 24 anos, foi possível verificar a desvalorização da fachada devido à falta de manutenção e limpeza periódica. Também a importância do projeto de fachada para evitar e/ou minimizar este tipo de manifestação. Já as edificações "B" e "C", mesmo tendo menores idades de uso, apresentaram manifestações patológicas relevantes, como fissuras por diferentes causas e falhas de execução

Os prováveis diagnósticos das manifestações foram por movimentação térmica, inexistência de projetos de fachadas de revestimento argamassado, falha na execução, falta de manutenção, inexistência e uso deficiente de verga e contraverga, esquecimento de materiais ou má limpeza do substrato, movimentação higroscópica ou expansão da argamassa de assentamento. Porém, onde foram obtidos dois ou mais diagnósticos é necessário a realização de ensaios complementares para obter a causa correta.

\section{CONCLUSÕES}

A partir dos resultados obtidos é possível constatar que a captação de imagens do VANT possui amplo potencial de utilização possibilitando a identificação, pelo profissional, de manifestações como manchas de sujeira, expansão no revestimento e/ou pintura, falhas de execução e fissuras tanto horizontais como verticais, em edificações de até 16 pavimentos, garantindo segurança, eficiência e baixo custo operacional da inspeção, além de oferecer ao profissional ex perimentado a possibilidade de realizar avaliação pontual. Porém, o uso do veículo aéreo não tripulado não dispensa a realização de inspeções invasivas que permitam observar o interior do revestimento para verificar o fator causador correto da manifestação.

\section{REFERÊNCIAS}

Associação Brasileira de Normas Técnicas (2005a). NBR 15220-2: Desempenho térmico de edificações - Parte 2: Métodos de cálculo da transmitância térmica, da capacidade térmica, do atraso térmico e do fator solar de elementos e componentes de edificações. ABNT. Rio de Janeiro.

Associação Brasileira de Normas Técnicas (2005b). NBR 15220-3: Desempenho térmico de edificações - Parte 3: Zoneamento bioclimático brasileiro e estratégias de condicionamento térmico passivo para habitações de interesse social. ABNT. Rio de Janeiro.

ASHRAE Handbook (2005), Fundamentals. Inch-Pound Edition. Supported by ASHRAE Research. American Society of Heating, Refrigerating and Air-Conditioning Engineers, Inc. 1791 Tullie Circle, N.E., Atlanta, GA 30329. ISBN 1-931862-70-2

Office of Energy Efficiency \& Renewable Energy (--), Building Energy Software Tools Directory. Disponível em: https://www.buildingenergysoftwaretools.com/. Acesso em: 24 abr. 2007.

Lamberts, R.; Dutra, L.; Pereira, F. O. R. (2004), Eficiência Energética na Arquitetura. 2ª edição. São Paulo: ProLivros.

Mendes, N.; Westphal, F. S.; Lamberts, R.; Neto, J. A. B. C. (2005). Uso de Instrumentos Computacionais para Análise do Desempenho Térmico e Energético de Edificações no Brasil. Ambiente Construído, Porto Alegre, v.5, n.4, p. 47-68, out./dez.

Ordenes, M.; Pedrini, A.; Ghisi, E.; Lamberts, R. (2003). Metodologia Utilizada na Elaboração da Biblioteca de Materiais e Componentes Construtivos Brasileiros para Simulações no Visualdoe-3.1. Relatório Interno - Departamento de Engenharia Civil, UFSC, Florianópolis.

Santana, M. V. 2006.Influência de parâmetros construtivos no consume de energia de edifícios de escritório localizados em Florianópolis - SC. Dissertação de Mestrado, Departamento de Engenharia Civil, UFSC, Florianópolis

Tommerup, H.; Rose, J.; Svendsen, S. (2007). Energy-efficient houses built according to the energy

B. G. WALTER, et al 
performance requirements introduced in Denmark in 2006. Energy and Buildings, v.39, n.1, p 11231130.

Westphal, F. S.; Lamberts, R. (2005), Building Simulation Calibration Using Sensitivity Analysis. In: Building Simulation, Ninth International IBPSA Conference Montréal, Canada August 15-18, 2005

Wong, N.H.; Li, S. A (2007), A study of the effectiveness of passive climate control in naturally ventilated residential buildings in Singapore. Building and Environment, v.42, n.1, p 1395-1405. https://doi.org/10.1016/j.buildenv.2005.11.032

Britez, C; Pacheco, J; Carvalho, M; Helene, P. (2017), Arquitetura planejada visando a longevidade de estruturas de concreto. In: Anais do $59^{\circ}$ Congresso Brasileiro do Concreto, Bento Gonçalves/RS.

Carvalho, Y.N.P; Leandro, F.S; Junior, F.C.N.G, Lêu, A.A.M; Silva, U.R.L. (2017), Manifestações patológicas com foco em fachadas de conjunto habitacional de baixa renda na cdade de Juazeiro do Norte/CE. In: Anais CONPAR- Conferência Nacional de Patologia e Recuperação de Estruturas, Recife, PE.

Da Paz, L.A.F., Costa, L.C.A., De Paula, M.O., Almeida, W.J.D., Fernandes, F.A.S. (2016), Levantamento de patologias causadas por umidade em uma edificação na cidade de Palmas - TO. Revista Eletrônica em Gestão, Educação e Tecnologia Ambiental, Santa Maria, v.20, n.1, p.174-180. 